\begin{tabular}{c} 
International Journal of Engineering \& Technology, $7(4.38)(2018) 783-787$ \\
SPC \\
Website: $w$ ww.sciencepubco.com/index.php/IJET \\
Research paper \\
\hline
\end{tabular}

\title{
Information Governance Implications on Social Solidarity Economy
}

\author{
Ahmad Fuzi Md Ajis ${ }^{1 *}$, Jafalizan Md Jali ${ }^{2}$, Siti Hajar Baharin ${ }^{1}$, Mad Khir Johari Abdullah Sani ${ }^{2}(\mathbf{P h D})$ \\ ${ }^{1}$ Faculty of Information Management, Universiti Teknologi MARA Cawangan Johor, Malaysia, \\ ${ }^{2}$ Faculty of Information Management, Universiti Teknologi MARA Kampus Puncak Perdana, Shah Alam, Malaysia
}

\begin{abstract}
Social and Solidarity Economy (SSE) initiative which has been implemented in Malaysia and shows it success when four case studies reported SSE communities or organization displayed efforts in helping the public on exiting economic crisis. However, the information miss-governance destroys the SSE business value, slow down organization and creates unnecessary risk to the SSE communities when the government and state neglected SSE successful initiatives in combating economic crisis of the public, yet not having them as a solution to the economic downturn. A case study was conducted to identify implication of information governance towards social solidarity economy initiative. Information Governance Framework were tested to two focus group using empirical study. The framework was simulated on the focus group to analyze its significant impact. The results of the study indicates that information governance increase income generation with significant achievement. The results of this study is important to demonstrate application of IG towards SSE decreases opportunity of business operation mistakes and dark data composition.
\end{abstract}

Keywords: Information Governance (IG), Social Solidarity Economy (SSE), SSE Initiative, Dark Data Composition, Business Operation, Value Optimization

\section{Introduction}

Social Solidarity Economy (SSE) in Malaysia formed based on four components which can be quadrantile into: (1) cooperatives; (2) social enterprises; (3) civil society organizations that run economic activities; and (3) mutual benefit societies25. A non-profit endeavor in realizing solidarity economy seems very challenging as we are looking into capitalist economic system which also striving in the fluctuating economic situation. However, the researcher aims to provide an open way to embrace solidarity economy in Malaysia by having information governance as the lubricants to the economic system.

Information Governance (IG) is an adaptation of information management including records management and retention, archiving, business analytics and IT governance in controlling and connecting enterprise information1. It is a discipline that includes people, processes, policies, and metrics for the oversight of enterprise information to improve business value.

SAP Thought Leadership Paper 2014 stated information governance could improve business value, offers more business advantages, and shows clear benefits that companies have achieved through their own information governance initiatives, so that this will urge the government to construct viable policy in strengthening the country's economy by looking at SSE initiatives.

Moreover, information governance could be bridging the gap of self-established SSE community and oblivious government policy on non-profit economic initiatives using few measures such as the occurrence of Big Data, Internet of Thing, Mobile Devices, and Social Media. However, further study must be implemented as the information governance practice need to be aligned with Malaysia's environment.
Information governance is a business issues that should be aligned with risk management strategy to leverage information assets, especially owned by SSE community to achieve their endeavor. In Malaysia perspective, Tan 25 provide a glimpse of challenges faced by the SSE organization to survive in Malaysia economic environment, which displayed there are no standard policy and legislative protecting the right of the SSE organization and supporting them in their economic activities. Therefore, the study aims to identify IG implications on SSE initiatives.

\section{Research design}

Literature review was done to collect empirical evidences to develop a conceptual framework for the study. Literatures pertaining to information governance analyzed to obtain elements of IG practices and variables studied were listed in Fig. 1.

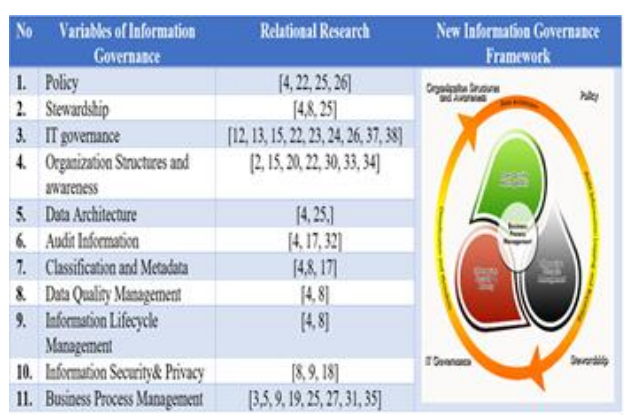

Fig. 1: A new framework model of information governance based on research studies and practices analyzed. The researcher categorized the variables of information governance to integrate multiple perspectives into similar categories. Then an empirical study was executed on the focus group using the new framework model. 
The new IG framework then integrated with Solidarity Economy (SE) processes ${ }^{19}$ in the Business Process Management. It is a continuity of processes involving: (1) Creation; (2) Production; (3) Exchange/Transfer; (4) Consumption/Use; and (5) Surplus allocation as shown in figure 2. Figure 3 shown the illustration of the steps in research design in its entirety in conducting focus groups and reporting on the results. This empirical study used five-stage process as a guide that will contribute to the completion of an impactful focus group. Data is collected through a semi-structured group interview process. Focus groups are moderated by a group leader and generally used to collect data on a specific topic. The focus group only involved 3 entities which consist of moderator, observer, and participants.

Focus groups conducted based on few segmentations as in Fig. 3 which are: (1) IGSSE-FG; (2) and B-FG. To pursue SSE characteristics, each focus group represent by similar characteristic whereby each participant should not have any experience in any of IG and SSE practices and having low income family background (below MYR3000/month). There were 8 undergraduate students from Faculty of Information Management, Universiti Teknologi MARA Cawangan Johor were selected and divided into 2 focus groups which each consist of 4 participants. Each focus group was given with the same tasks to be completed within 3 months; (1) establish an enterprise; (2) to generate minimum income of MYR1000 per month. Before completing the task, they were instructed to have 3 weeks course based on their segmentation. Only IGSSE-FG was trained with IG Framework approach. IG framework approach train the focus group on all 11 variables of IG and ways to apply each variable in the task.

First approach of IG Framework is policy since it creates big impact to the whole business processes. Therefore, during the short course, the moderator trained the participants using IG policy. This policy has also covered all variables of IG framework.

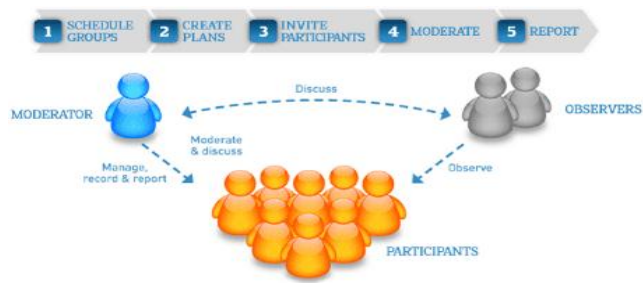

Fig. 3 : Focus group segmentation - IG-SSE Focus group (IGSSE-FG) incorporate IG framework in their enterprise but not Basic Focus Group (B-FG).

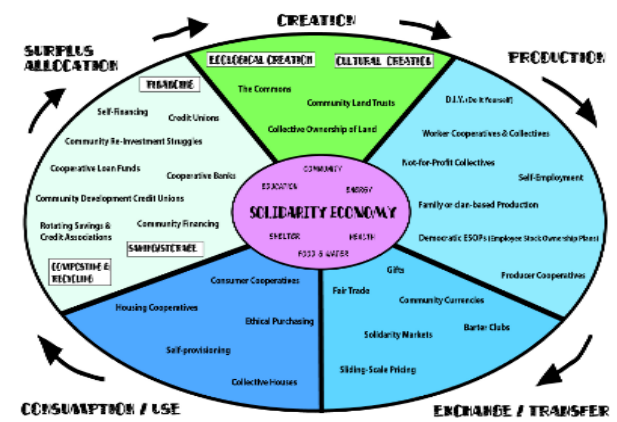

Fig. 2 : Solidarity Economy as a process: engagement of the processes with information governance framework creates strong enterprise and increase business performance.

Stewardship elements requires participants to engage in data management in the sense of data appropriate use and accessibility. Responsibility of participant to be a custodian of information which relies on the efficiency and effectiveness of IT as enablers ${ }^{4}$. Stewardship is considered as essential elements in the IG application as it defines the data experts who knows which data should be owned by whom.
IT Governance practice in this study is limited to the use of technology to manage and record all information related to the business which provide storage, prompt access and discovery to any information needed by the participants as the computer application is provided by the researcher.

Organization structure and awareness reflects the hierarchical responsibility and training on the IG practice. Leader of IGSSEFG group was taught to follow IG framework and guideline as to guide their members to achieve objective of the task.

In the second layer of the IG framework, continuity of operation on data architecture, audit information and classification and metadata were done with the supervision of moderator. The scope of data architecture was directed to data validation, storage, access, analyze and reports. Besides, audit information focuses on the policy compliance while classification and metadata operation emphasis on the categorization of information to enable effective search and accessibility.

Data quality management is important to determine quality reporting on the business performance. In this study, each data to be used for any decision making for the enterprise evaluated by technical dimension of data quality ${ }^{8}$ which are; valid, unique, complete, consistent, timely, accurate and precise.

This process will reflect to the next operation, Information Lifecycle Management (ILM). The ILM address the entire lifecycle of data and information including their creation, retention, and deletion. The entire lifecycle was monitored using the next process which is Information Security and Privacy (ISP). ISP allows only selected parties to access the all information exist. As for this research, the participants can only record the information but not deletion.

Business process management represent the processes involved in running the enterprise. Its focus is on the value of information that helps to drive the profit or objective of the enterprise, besides the actual business processes including integrated marketing plan, operation management and financial administration.

\section{Results and discussion}

After three months, all focus groups were called for document analysis and an interview session to analyze the achievement of research objective. According to the result of document analysis, all the task given to both focus groups completed successfully whereby each focus group successfully established an enterprise and able to generate income of minimum MYR1000 per month.

Figure 4 indicates total net income for both focus group within three months of enterprise operation. Even though both focus group are having the same industry types, which is Telecommunication Industry, different income generated was reported. IGSSEFG generated of total MYR12,459 which is MYR4,153 nett income per month on average. B-FG generated MYR4,080 for three months which equivalent to average of MYR1,360 nett income per month.

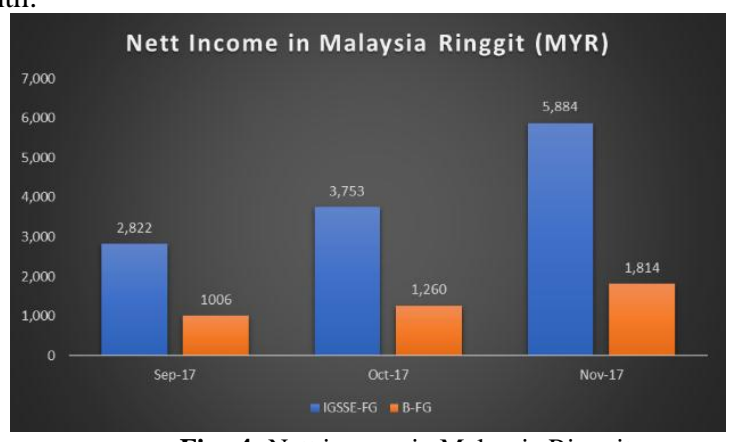

Fig. 4: Nett income in Malaysia Ringgit

Figure 5 reflects the performance of enterprise for each focus group and it indicate significant difference of performance between both. Surprisingly, IGSSE-FG achieve 57\% increment in perfor- 
mance after 3 months with IG approach while B-FG only achieve $44 \%$.

An interview session was conducted after the document analysis to investigate the implication of IG approach towards SSE initiatives and the business processes. Based on the interview, B-FG emphasized that the business process become a routine, but it was very challenging to increase the net income to be more than MYR1,000 per month. IGSSE-FG indicates that the business processes management become much easier when their enterprise reached the third month of operation as the IG approach become familiar to be executed.

All issues and challenges faced by B-FG group listed and aligned with IG 11 variables to identify each issue's consequences as in figure 6 to demonstrate the importance of IG reliance.

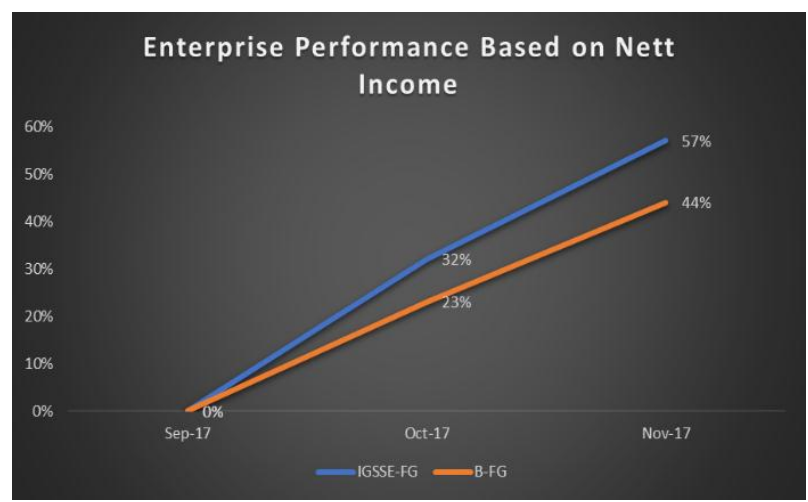

Fig. 5 : Enterprise Performance Based on net income within 3 months of operation.

\begin{tabular}{|c|c|c|}
\hline Variables of IG & Issues & Consequences \\
\hline Policy & $\begin{array}{l}\text { Decision making process was } \\
\text { inconsistent and structured and } \\
\text { consistent procedure is not executed. }\end{array}$ & $\begin{array}{l}\text { Same issues were dealt with different } \\
\text { procedures and different results } \\
\text { occurred. }\end{array}$ \\
\hline Stewardship & $\begin{array}{l}\text { There were no data experts to } \\
\text { safeguard and manage the valuable } \\
\text { data. }\end{array}$ & $\begin{array}{l}\text { Valuable data may become dark data } \\
\text { (unused and abandoned). }\end{array}$ \\
\hline IT governance & $\begin{array}{l}\text { No specific storage and data } \\
\text { accessibility cannot be requested } \\
\text { promptly due to manual procedure. }\end{array}$ & $\begin{array}{l}\text { Cost of operation increase, and data } \\
\text { discovery consume a lot of time. }\end{array}$ \\
\hline $\begin{array}{l}\text { Organization } \\
\text { Structures and } \\
\text { awareness }\end{array}$ & Not expose to IG and its importance. & $\begin{array}{l}\text { Decrease profit maximization increase } \\
\text { operational cost. }\end{array}$ \\
\hline $\begin{array}{c}\text { Data } \\
\text { Architecture }\end{array}$ & Data were scattered and not analyzed. & Increase in dark data. \\
\hline $\begin{array}{c}\text { Audit } \\
\text { Information }\end{array}$ & No audit was made. & $\begin{array}{l}\text { Loss of valuable data and decrease } \\
\text { income generation. }\end{array}$ \\
\hline $\begin{array}{l}\text { Classification } \\
\text { and Metadata }\end{array}$ & $\begin{array}{l}\text { Information hardly found and } \\
\text { inaccessible. }\end{array}$ & $\begin{array}{l}\text { Similar data which consist of valuable } \\
\text { information may be discarded. }\end{array}$ \\
\hline $\begin{array}{l}\text { Data Quality } \\
\text { Management }\end{array}$ & $\begin{array}{l}\text { Data on feedback and retention of } \\
\text { prospect and customer was not } \\
\text { administered. }\end{array}$ & $\begin{array}{l}\text { Performance improvisation hardly } \\
\text { made. }\end{array}$ \\
\hline $\begin{array}{l}\text { Information } \\
\text { Lifecycle } \\
\text { Management }\end{array}$ & $\begin{array}{l}\text { Information created without specific } \\
\text { requirement, unmanaged, and } \\
\text { deletion was not controlled by } \\
\text { specific procedure. }\end{array}$ & $\begin{array}{l}\text { Information explosion and deletion of } \\
\text { valuable confidential information } \\
\text { happened. }\end{array}$ \\
\hline $\begin{array}{l}\text { Information } \\
\text { Security\& } \\
\text { Privacy }\end{array}$ & $\begin{array}{l}\text { All members have access to all } \\
\text { documents. }\end{array}$ & $\begin{array}{l}\text { Safety and confidentiality breach of } \\
\text { information may harm the whole } \\
\text { business. }\end{array}$ \\
\hline $\begin{array}{l}\text { Business Process } \\
\text { Management }\end{array}$ & $\begin{array}{l}\text { Objective is achieved with minimal } \\
\text { achievement. }\end{array}$ & $\begin{array}{l}\text { Information was not valued to be used } \\
\text { for business improvisation. }\end{array}$ \\
\hline
\end{tabular}

Fig. 6: Enterprise Performance Based on net income within 3 months of operation

The biggest issue of IG is the policy compliance as it determines the successful practice of IG. A practice of valuing information by engaging in structured policy making could help the enterprise to be focus and solve any issues using standardized methods. It is a discipline of the people in the organization in managing the development of information and data to obtain quality data needed for transaction and analytic processing8.

Dark data is a composition of valuable data but abandoned or ignored without being tapped to be used for the organization's benefits. In fact, the composition of dark data happened all the time if there are no data experts to identify and analyze it to become useful ${ }^{4}$. Stewardship of dark data could optimize the business process in simpler manner.

In this study, the implementation of IT governance is only limited to storage, access, and discovery. Even though the IT governance scope is limited, manual procedure could increase the overhead cost of the enterprise and consume a lot of time in executing data discovery. ${ }^{3,22,26}$

Awareness of IG create significant increase in IGSSE-FG as the amount of income generated almost 4 times bigger than B-FG after the third month. Therefore, exposure to IG create structured and procedural operation which indirectly assure the achievement of objective is beyond expectation due to the reliance of dependable quality data.

Process of data validation, storage, access, analyze and reports in data architecture is important in managing information properly for discovery and business usage. However, inexistence of data architecture contributes to dark data creation which already consume space and increase unnecessary expenditure of the business. ${ }^{25}$

Besides, Audit Information and Logging report define the compliance of the business to its policy. Besides its enable the organization to investigate any drawbacks and create spaces for any improvement to the current business operation. ${ }^{4}$ Loss of valuable data and decrease in income generation which was faced by B-FG due to no audit activity or reports which will help them to oversee the whole business operation condition.

Furthermore, prompt discovery of information is needed for business purposes as to analyze and extract information from available data. These require proper classification and metadata operation to control all access points and tertiary data which will lead to the appropriate information. Inaccessibility could occur whenever the data or information is misclassified or mislead ${ }^{8}$. Besides, duplication of similar data will exist and increase operational cost of the enterprise. Repetition of handling duplicated data would create unnecessary environment between consumers and the enterprise. On the other hand, data quality management is crucial in assuring accurate and precise decision making. Having many data does not provide opportunity of having quality data if it is not valid, unique, complete, consistent, timely, accurate and precise. ${ }^{4,8}$ Total data quality management could not be achieved if the first and second layer of IG framework is not applied. Data quality management is beneficial towards optimizing the value creation of information in supporting the enterprise to achieve its objectives in the long run. Most enterprise would look into financial data to foresee the upcoming opportunity for the business venture however, considering the dark data is also opportunity to open new gateway of business potential.

An appropriate data quality management will ease the process of information lifecycle management. ILM deals with the entire lifecycle of a data through its creation, retention and deletion. On the other hand, the major concern is on the retention and deletion of data rather than its creation. Issues on how long the data should be retain and in what format may urge the enterprise to spend more on the storage technologies. Organizational retention requirement and regulatory retention management are some of the major concern in retention specification of files. ${ }^{4,8}$

The highest priority of the total IG approach is Information security and privacy. It defines the trade secret of the enterprise as well as the strength of the company to remain exist and competitive in the industry. Prompt access and discovery contributes to smooth operation of business venture while the information privacy is at risk when the security is not part of the major concern. A lot of scholars discusses on the aspect of Information security and privacy as the privileges of utilizing the data depend on three major components; people, process and technology ${ }^{8,9,18}$. Privileges of creation, read, update and deletion of data should be monitored to prohibit unethical access of non-stakeholders into critical information like critical financial information, customer and employee data.

Business processes management become more manageable after all IG variables defined properly as the lubricants of the entire 


\section{Conclusions}

Information Governance approach assist every aspect of business processes in terms of optimization value of information. Its implication towards SSE initiatives creates an opportunity for the participants to make use of their limited resources in order to achieve the objectives. Even though the inexistence of IG in the business venture does not forbid the enterprise to achieve the objective but it does not place the business to its maximum potential.

Currently, exponential advancement of internet of things boost the dissemination of information faster to wider coverage recipients. The leverage of technology makes up creator of information become anonymously created and enormous amount of data being spread all day long. Simultaneously, the governance of information being alerted by information professional in controlling unauthorized and malicious information since the creation of information is not controlled.

Information governance focus on the effort concerning records management, privacy regulation, information security, data flows and ownership, and data lifecycle management. ${ }^{6}$ Besides, information governance is highly relevant with the distribution of information. ${ }^{9}$ However, these practices are influenced by its interaction $^{14}$ as the pattern of interaction differs from the actor of the information, who is both sender and receiver of information. In fact, the exchange of information via interaction is not lying on the statement of information itself but an interaction of people, situations, and knowledge. These environments could possibly change the value of information in many ways. Therefore, governance of information should be considered with the inclusion of the sense making interactions aspects to understand and utilize the information's value. ${ }^{18}$

In this study, the information governance represent the practices of value maximization of information. It represents IG as a solidarity practice of valuing organizational information which place a responsibility of the entire enterprise to get involved in the implementation of information governance as the governing actor. Since each country have their own governor, now is the time where information governor should be established. IG is not a practice of a person, but a team effort towards optimization of information value.

For future research, the study recommend the IG approach to be tested in an established organization as the IG framework is flexible and need to be tailored according to organizational structure and operations. Besides, implementation of IG in organization is not concern on how robust is your policy but, it concern of the level of effectiveness of the organizational IG program.

\section{Acknowledgments}

This project is financially supported by the Ministry of Higher Education Malaysia under Fundamental Research Grant Scheme (600-IRMI/FRGS 5/3 (054/2017).

\section{References}

[1] Blair, B. T. VIALUMINA. Why information governance? 2011. 20 October 2017. http://mimage.opentext.com/alt_content/binary/pdf/ViaLuminaInformation-Governance-Executive-Brief-Why-InformationGovernance.pdf

[2] Boh, W.F., and Yellin, D. Using enterprise architecture standards in managing information technology. Journal of Management Information Systems, 23, 3 (2006), 163-207.

[3] Brown, C.V., and Magill, S.L. Reconceptualizing the contextdesign issue for the information systems function. Organization Science, 9, 2 (1998), 176-194.

[4] Compert, C, Milman, I., Jesionowski, T., Ballard, C., Smith, H. C., Rosen, B. and Bill Plants. Information Governance Principles and Practices for a Big Data Landscape . US :IBM Redbooks, 2014.
[5] De Haes, S., and Van Grembergen, W. An exploratory study into IT governance implementations and its impact on business/IT alignment. Information Systems Management, 26, 2 (2009), 123-137.

[6] Donaldson, A. and P. Walker. "Information governance: A view from the NHS." International Journal of Medical Informatics 73 (2004): 281-284

[7] ESI. Information Governance: Executive briefing book. 2017. 10 October

<https://www.esi.ac.ma/Dossiers/20140709040704.pdf>

[8] Giordano, A.D. (2014) Performing Information Governance: A Step-by-Step Guide to Making Information Governance Work. IBM Press Pearson.

[9] Hoefnagel, Ellen, Birgit de Vos and Erik Buisman. "Marine informational governance, a conceptual framework." Marine Policy 42 (2013): 150-156.

[10] Information Governance Initiative. Information Governance Reference Model (IGRM) Guide. 2016. 12 October 2017. <http://www.edrm.net/resources/guides/igrm/usingmodel>.

[11] Kirsch, L. Deploying common systems globally: The dynamics of control. Information Systems Research, 15, 4 (2004), 374-395.

[12] Kirsch, L. Portfolios of control modes and IS project management. Information Systems Research, 8, 3 (1997), 215-239.

[13] Kirsch, L. The management of complex tasks in organizations: Controlling the systems development process. Organization Science, 7, 1 (1996), 1-21.

[14] Kooiman, J., ed. Fish for life, interactive governance for fisheries. Amsterdam: Amsterdam University Press, 2005.

[15] Kooper, M.N., Maes, R., \& Lindgreen, E.E.O. R. (2010). On the governance of information: Introducing a new concept of governance to support the management of information. International Journal of Information Management, 31(2011). 195-200.

[16] Kooper, M.N.; Maes, R.; and Roos Lingreen, E. On the governance of information: Introducing a new concept of governance to support the management of information. International Journal of Information Management, 31, 3 (2011), 195-200.

[17] Lea, William. Information: To share or not to share? The Information Governance Review. 2013. 18 October 2017 <https://www.ed.ac.uk/files/imports/fileManager/Caldicott\%20Gua rdianInfoGovernanceaccv2\%20pdf.pdf >

[18] M.N. Kooper, et al. "On the governance of information: Introducing a new concept of governance to support the management of information." International Journal of Information Management 31 (2011): 195-200

[19] M.R, Fazlidaa, Jamaliah SaidInformation Security: Risk, Governance and Implementation Setback. Procedia Economics and Finance 28 (2015) $243-248$

[20] Miller, Ethan. "Solidarity economy: key conceot and issues." Solidarity Economy I: Building Alternatives for People and Planet. Ed. Emily Kawano, Tom Masterson and Jonathan Teller-Ellsberg. MA Center for Popular Economics, 2010. 1-12.

[21] Otto, B. Organizing data governance: Findings from the telecommunications industry and consequences for large service providers. Communications of the Association for Information Systems, 29, 3 (2010), 45-66

[22] Peterson, R. Crafting information technology governance. Information Systems Management, 21, 4 (Fall 2004), 7-22.

[23] Raghupathi, W. Corporate governance of IT: A framework for development. Communications of the ACM, 50, 8 (2007), 94-99.

[24] Sambamurthy, V., and Zmud, R. Arrangements for information technology governance: A theory of multiple contingencies. MIS Quarterly, 23, 2 (1999), 261-290.

[25] Sana Bent Aboulkacem Guetat and Salem Ben Dhaou Dakhli. The Architecture Facet of Information Governance: The Case of Urbanized Information Systems. Procedia Computer Science 64 (2015) $1088-1098$

[26] Tallon, P.P. Understanding the dynamics of information management costs. Communications of the ACM, 53, 5 (2010), 121-125.

[27] Tallon, P.P.; Kraemer, K.L.; and Gurbaxani, V. Executives' perceptions of the business value of information technology: A processoriented approach. Journal of Management Information Systems, 16, 4 (Spring 2000), 145-173.

[28] Tan, J.-E. Social and Solidarity Economy for Sustainable Development in Malaysia: Concepts, Contexts and Case Studies. UKM Ethnic Studies Paper Series. (2016)

[29] The future of enterprise information governance. Economist Intelligence Unit, New York, 2008.

[30] Tiwana, A. Governance-knowledge fit in systems development projects. Information Systems Research, 20, 2 (2009), 180-197. 
[31] Tiwana, A., and Konsynski, B. Complementarities between organizational IT architecture and governance structure. Information Systems Research, 21, 2 (June 2010), 288-304.

[32] Veristas Technologies. State of Information Governance $2016 \mathrm{Re}$ port. $2017 . \quad$ November 2017 <https://www.veritas.com/content/dam/Veritas/docs/reports/stateof-information-governance-report.pdf>

[33] Watson, H.; Fuller, C.; and Ariyachandra, T. Data warehouse governance: Best practices at Blue Cross and Blue Shield of North Carolina. Decision Support Systems, 38, 3 (2004), 435-450.

[34] Weber, K.; Otto, B.; and Österle, H. One size does not fit all: A contingency approach to data governance. Journal of Data and Information Quality, 1, 1 (2009), 1-27.

[35] Weill, P., and Ross, J.W. IT Governance. Boston: Harvard Business School Press, 2004.

[36] Willson, P., and Pollard, C. Exploring IT governance in theory and practice in a large multinational organisation in Australia. Information Systems Management, 26, 2 (2009), 98-109.

[37] Xue, L.; Ray, G.; and Gu, B. Environmental uncertainty and IT infrastructure governance: A curvilinear relationship. Information Systems Research, 22, 2 (2011), 389-399.

[38] Xue, Y.; Liang, H.; and Boulton, W. Information technology governance in information technology investment decision processes: The impact of investment characteristics, external environment, and internal context. MIS Quarterly, 32, 1 (2008), 67-96. 